\title{
Learning Difficulties in Malayalam and Mathematics of Standard VI Learning Disabled Students in Kerala
}

\author{
${ }^{1}$ Sheeja.T.V, ${ }^{2}$ Dr.P.K.Aruna \\ (Calicut University Teacher Education Centre Chakkittapara Calicut,Kerala,India) \\ (Department of Education Calicut University Calicut, Kerala,India)
}

\begin{abstract}
The children with slow learning, Children with language disorders (Reading Writing and spelling disorders) and children with physical and mental disability these children's physical needs, social, psychological and instructional needs are entirely different from normal children they need special materials, instructional techniques and facilities to compensate their disabilities or to promote their abilities with in the class room or outside the class room of normal schools and special school
\end{abstract}

\section{Introduction}

Education is the fundamental right of citizens of India irrespective of their caste, creed, colour and sex. The same is applicable to the children with abilities and disabilities. In the western world, a good literature in the form of books, identification and assessment tools, well structured and organized educational programmes and rehabilitation services are available for individuals with abilities and disabilities. In India such things are scanty, and people are not aware of the needs of special children and even the available programmes are not reaching the needy. Even after 50 years of independence, the Government of India has not achieved the objective of Universalisation of Elementary Education/Primary Education.

These children's physical needs, social, psychological and instructional needs are entirely different from normal (average) children. They need special materials, instructional techniques and facilities to compensate their disabilities or to promote their abilities within the classroom or outside the classrooms of normal schools and special schools. Special Education is nothing but the specially designed instructional programmes, which are applied to exceptional children such as physically handicapped, hearing impaired, visually impaired and orthopedically handicapped children, and mentally retarded, gifted slow learners and children with learning difficulties. These instructional programmes are different from the education of normal children but they are equally good to educate normal children.

\section{Need And Significance Of The Study}

It is true that educationally backward children, handicapped children and gifted children are in need of specific facilities for their optimum development. Educators feel the importance of designing special instruction for the benefit of special children. The proponents of special education put forth the following reasons in support of their argument. Special classes are very essential for educationally backward children because they are very much require specific teaching methods to circumvent their deficiency. A normal classroom generally consists of children who belong to diverse categories such as below average, average, bright, both physically and mentally handicapped, emotionally disturbed, learning disabled and slow learners. A classroom teacher usually finds it very difficult to device his instruction, so as to reach out to all these categories. Hence special education is not only meant to enable the special children to surmount their learning problems but is also conducive for regular class room teachers. Education begins where medicine ends. It is of medical concern to provide a hearing aid to hard of hearing children. But teaching the children to use their residual vision or hearing capacities effectively is certainly an educational function. This warrants special education for these children. It is not possible to ensure optimum human resource development without developing the potentials of special children. Special equipment and additional training are quite, necessary for teaching children which are expensive and need adequate budgetary provisions.

\section{The special education for Learning Disabled Children}

The study of special children is the study of differences. The special child is different in some way or the other from the average child. In very simple term, "a special child is one who may have problems or special talents in thinking, seeing, hearing, speaking, socializing or moving." A special child is a combination of special abilities or disabilities. These children are either far enough below or far enough above the average range. They need very much specialized attention, which is not provided in regular class rooms. Special children are those students who require education and related services if they are to realize their full human potential. These 
children are in need for special education because are markedly different from most children in the class room in one or more of the following ways.

\section{Variables Of The Study}

a) Learning difficulties and intelligence are the Independent Variables.

b) Basic Writing Skills in Malayalam, Basic Reading Skills in Malayalam and Mathematics Operation Skills are Dependent Variables.

\section{Objectives Of The Study}

1. To identify difficulties in the Learning of Basic Reading Skills in Malayalam, the Basic Writing Skills in Malayalam and the Basic Mathematics Operation Skills.

2. To find out the percentage of various difficulties of Learning disabled students in Basic Writing Skills in Malayalam and Basic Reading Skills in Malayalam and Mathematics Operation Skills.

3. To find out the percentage of the factors related to "Writing and Reading" ability in Malayalam and basic Mathematics Operation Skills. 4. To find out whether there exist significant difference in the mean scores of Intelligence, Basic Writing and Reading Skills in Malayalam, Basic Mathematics Operation Skills and Learning difficulties between Learning Disabled boys and girl students.

5. To find out whether there exist significant difference in the mean scores of intelligence, Basic Writing and Reading skills in Malayalam, Basic Mathematics Operation Skills and Learning Difficulties between Learning Abled boys and girl students.

6. To find out whether there exist significant difference in mean scores of Intelligence, Basic "Writing and Reading Skills" in Malayalam, Basic Mathematics Operation Skills and Learning Difficulties between Learning Disabled and Learning Abled Students (normal) in the total sample.

7. To find out the extent of relationship between Intelligence and Learning difficulty of Learning Disabled and Learning abled students (normal) in the total sample and sub samples male and female.

8. To develop an observation schedule for identifying Learning Disabled to compare the Learning Disabled and Learning Abled students (normal) with regard to difficulties in Basic Writing and Reading Skills in Malayalam and Basic Mathematics Operation Skills.

9. To analyse teachers and parents opinion regarding Learning Disabled students difficulties faced by them in academic and non academic areas.

HYPOTHESES OF THE STUDY

1. There exists significant difference in the mean scores of Intelligence, Basic Writing and Reading Skills in Malayalam, Basic Mathematics Operation Skills and Learning Difficulties between Learning Disabled Boys and Learning Disabled Girl students.

2. There exists significant difference in the mean scores of Intelligence Basic Writing and Reading Skills in Malayalam, Basic Mathematics Operation Skills and Learning difficulties between Learning Abled boys and Girl students.

3. There exists significant difference in mean scores of Intelligence, Basic Reading and Writing skills in Malayalam and basic Mathematics Operation Skills and Learning Difficulty between Learning Disabled and Learning Abled students (normal) in the Total Sample.

4. There exists significant relationship between Intelligence and Learning Difficulties of Learning Disabled and Learning Abled students (normal) in the total sample and sub-sample Male and Female.

Survey method

\section{Methodology Of The Study}

With a view of realizing the major objectives of the study survey method is adopted. It involves finding out Learning difficulties in Basic Writing and Reading Skills in Malayalam and Mathematics Operation Skills of Standard VI learning disabled students in Kerala. The survey method gathers data from a relatively large number of cases in a particular type. It is concerned with the generalized statistics that results in data abstracted from a number of individual cases.

Sample

There are two phases in the selection of samples.

1. First phase: In the first phase '600' students were drawn from Thrissur, Calicut, Kannur and Malappuram districts of Kerala, by using stratified random sampling method. The following factor was taken into consideration while selecting the sample: 1) Sex of the sample.

2. Second Phase: In the second phase, from the initial sample 52 learning disabled children were drawn by purposive sampling by using observation schedule for identifying learning difficulties of learning disabled students for teachers, questionnaire for identifying learning difficulties for teachers and parents, applying inclusionary and exclusionary criteria and using school records. 
Tools Used

1. Observation Schedule for Identifying Learning Difficulties of Learning Disabled Students for teachers (Aruna and Sheeja, 2009).

2. Schedule for Validating Observation Schedule for Identifying Learning Difficulties of Learning Disabled Students (Aruna and Sheeja, 2009).

3. Questionnaire for Identifying Learning Difficulties for Teachers (Aruna and Sheeja, 2009)

4. Questionnaire for Identifying Learning Difficulties for Parents (Aruna and Sheeja, 2009)

5. Test of Basic Reading Skills in Malayalam (Aruna and Sheeja, 2009)

6. Test of Basic Writing Skill in Malayalam (Aruna and Sheeja, 2009)

7. Test of Basic Mathematics Operation Skills (Aruna and Sheeja, 2009)

8. Raven's Standard Progressive Matrices Test: SPMT (Raven, 1958).

\section{Statistical Techniques Used} hypotheses.

The investigator used the following techniques for testing the objectives of the study and specific

Major analysis included the following techniques

1. Percentage analysis.

2. Test of significance of difference between means of large independent sample.

3. Pearson's coefficient of correlation (r).

4. Test of significance of correlation coefficient.

Investigation of group difference of Intelligence, Basic Writing and Reading Skills in Malayalam, Basic Mathematics Operational Skills and Learning Difficulties between Boys and Girls in Total Sample (N $=600$ )

\section{Analysis Of Percentage Of Various Learning Disabled And Learning Abled Students In Total Sample (N} =600)

1. Out of 600 students $8.6 \%$ were identified as learning disabled children. The total number of learning disabled among 600 is 52 .

2. The remaining 548 students were learning abled or normal, ie. $91.33 \%$ of the sample.

3. Analysis of the results of the Teachers Observation Schedule and Questionnaire; and Parents Questionnaire also reveals the same.

4. The findings of the study prove that learning difficulties of learning disabled are due to pre-natal $(60 \%)$, perinatal $(70 \%)$ or post-natal $(90 \%)$ causes.

5. Learning difficulties are curable up to $80 \%$, if early intervention is possible.

6 . The study proves that teachers viewed that at least, $8 \%$ of students of Standard VI have at least one difficulty related to learning and $8.6 \%$ of students have two and more difficulties. The total number of students of Standard VI experiencing Learning Difficulties were $8.6 \%$.

7. Among 600 students the most prevalent difficulty is social and emotional problems $8 \%, 7.33 \%$ have the second most learning difficulty, ie. Reading difficulty. $6.5 \%$ have writing difficulty $6 \%$ have mathematical difficulty, $5.17 \%$ have auditory difficulty, $2.5 \%$ have cognitive difficulty, $2.5 \%$ have visual difficulty, and the lowest occurring difficulty is motor problems, ie. $0.5 \%$.

8. Another findings is that among Reading Disabled of Standard VI, 2.16\% have Difficulty in Visual Letter Discrimination, 2.16\% have Difficulty in Nasal Sound Recognition, 2.76\% have Difficulty in Stress Sound Recognition, $2.33 \%$ have Difficulty in Consonant Letter Discrimination, $2.83 \%$ have Difficulty in Knowledge of Auxillary Symbols, 3.66\% have Difficulty in Knowledge of Non-Words, 3\% have Difficulty in Knowledge of Spelling, 3.33\% have Difficulty in Semantic Knowledge, 3.66\% have Difficulty in Oral Word Discrimination 3.66\% have Difficulty in Listening Comprehension, $3.33 \%$ have Difficulty in Reading Comprehension, 3.3\% have Difficulty in Letter Pronunciation, 3.33\% have Difficulty in Kagnitha Skills, $3.33 \%$ have Difficulty in Reading Text.

9. The analysis reveals that among Mathematics Disabled students of Standard VI, 1.66\% have Difficulty in Basic Number Skills, 1.66\% have Difficulty in Conversion of Number in to Words, $1.66 \%$ have Difficulty in Cardinality $2.16 \%$ have Wrong Concept on Base 10 Structure, $1.82 \%$ have Wrong Concept on Place Value, 2\% have Wrong Concept on Addition, 1.6\% have Difficulty in Subtraction, 1.82\% have Wrong Money Except, 1.82\% have Difficulty in Division, 2\% have difficulty in Concept of Time, 1.82\% have difficulty in Reading Calendar, $1.82 \%$ have Difficulty Multiplication, $2.16 \%$ have Difficulty in using Fraction, 2.16\% have Difficulty in using Symbols, $2.16 \%$ have Difficulty in using Shapes, $2 \%$ have Abstraction Difficulty. 
10. In this study, the findings, which are, the difficulties among 6th grade students in Writing Disbled, $1.82 \%$ have Difficulty in Using Alphabetic Knowledge, 2.5\% have Difficulty in Using Letter Discrimination, $2.33 \%$ have Wrong Word Recognition, $2.83 \%$ have Wrong Word Combining, $2.5 \%$ have Difficulty in Kagnitha Skill, 2.16\% have Using Wrong Vocabulary 3.16\% have Wrong Syntactic Skill, 2.16\% have Wrong Orthographic Skill, 3.16\% have Difficulty in Dictation Skill.

11. Analysis of Teachers opinion regarding Learning Disabled Students Difficulties faced by them in Academic and Non academic areas. $60 \%$ of the teachers opined that no training was provided in the schools for identifying learning disability for teachers in the schools. $100 \%$ teachers viewed that they have faced Problems in Teaching and Learning the Disabled Students 10\% of teachers not favoured Integrated Classrooms for the Learning the Disabled students. $86.6 \%$ teachers were not used by strategies other than activity methods. $26.8 \%$ teachers provide special care for teaching the learning disabled students. $90 \%$ teachers pointed out the need for providing training programmes for teachers so as to teach the learning disabled students effectively. 12. Analysis of Parents opinion regarding Learning Disabled students Difficulties faced by them in academic and non academic areas. $60 \%$ parents opined that mothers faced problems during prenatal period, $75 \%$ mothers said that they have facing problems during perinatal period, $90 \%$ mothers claimed that they have facing problem after delivery, $30 \%$ parents have awareness about learning difficulty. $40 \%$ parents viewed that the child need special training programmes. $40 \%$ parents discussed the teachers about learning difficulty of their children's in Mathematics Operation Skills, Reading and Writing in Basic Malayalam Skills.

\section{Conclusion}

After going through this study and various analysis of the different skills it is found out that the most occurring difficulty faced by the Learning Disabled students of Standard VI is socio-emotional problem and the least occurring difficulty is Motor Problems. Among difficulty in Reading Skills, Writing Skills and Difficulty in Mathematics Operational Skills the most prevalent difficulty is Reading difficulty (44\%). The second occurring difficulty in Writing difficulty (39\%). The third occurring difficulty is Mathematics Operational Skills (36\%). While comparing girls and boys students, Girls and boys are almost equal in showing their difficulties in Reading Skill, Writing Skill and Intelligence. But Girls show more difficulties in Mathematics Operational Skills.

\section{Educational Implications}

It is important to note that gender difference is a factor to show academic difficulties. But Intelligence is not a factor to effect Learning difficulties of Learning disabled students. Even high intelligent students also show learning disabilities. So both parents and teachers should be aware about the root causes of the Learning disability. Early intervention in one of the remedial measure because it gives them the solutions as early as possible.

\section{Journal papers}

[1]. Aaron,P.G (1991).Can reading disabilities be diagnosed without using intelligence tests? Journal of psychology and education. 178,156-197.

[2]. Adelman, P.B:Vigel,S.A.(1991).The learning disabled adult ”In B.Y.L. Wong (ed). Learning About Learning Disabilities, 564-594

\section{Books}

[3]. Adelman, H.S. and Taylor, L (1978). An Introduction to Learning Disabilities. London: Scott Foresan.

[4]. Catts, H.W. and Kamhi, A.G. (1999) Language and reading: Convergence and divergence. In H.W.Catts, and A.G.Kami (eds) language and reading disabilities, Boston: Allyn and Bacon.

[5]. Garrett, H.E. (1979). Statistics in Psychology and Education. Bombay: Feffer and Simons Ltd.

[6]. Hughes, M. (1986). Children and Number Difficulties in Learning Mathematics. Oxford: Basal Blackwell.

[7]. Kirk, S.A. (1979). Educating Exceptional Children, $3^{\text {rd }}$ edn. Boston: Houghton Mifflin. 